\title{
Notas sobre la diversidad latinoamericana. Un ensayo
}

\section{Notes on the Latin America Diversity. An Essay}

\section{Notas sobre inteligência americana. Um ensaio}

\author{
"Para que pudiera hablar, para que pudiera saber y saberse, \\ los primeros dioses enseñaron a los hombres y mujeres de maíz a soñar, \\ y nahuales les dieron para que con ellos caminaran la vida". \\ El viejo Antonio, Subcomandante insurgente Marcos.
}

Marcelo Valverde-Morales

Asistente Académico

Posgrado en Estudios Latinoamericanos

Universidad Nacional Costa Rica

Recibido: 20/11/2017 Aceptado: 12/2/2018

\section{Resumen}

El presente ensayo analiza y dialoga con la obra "Notas Sobre la Inteligencia Americana" de Alfonso Reyes. En él desarrollo un acercamiento a los principales aportes de Reyes, así como a las preguntas planteadas por el pensador con respecto al valor y el quehacer de la intelectualidad latinoamericana, relacionándolos a la contemporaneidad de la diversidad, la academia, la cultura y la sociedad de Nuestra América. El trabajo surge como parte de los esfuerzos y la labor de la

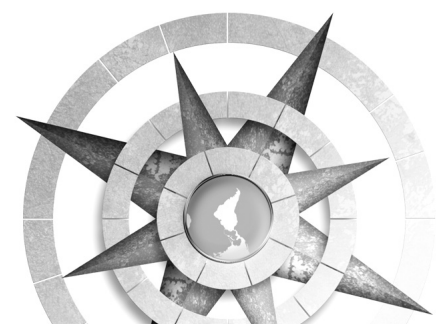

DOI: https://doi.org/10.15359/tdna.34-63.8
Maestría en Estudios Latinoamericanos del Instituto de Estudios Latinoamericanos, en abordar lo relativo al pensamiento latinoamericanista contemporáneo de la mano de las grandes propuestas intelectuales de Nuestra América.

Palabras clave: Pensamiento latinoamericano, ensayo latinoamericano, Alfonso Reyes, diversidad

\section{Abstract}

This essay analyzes and converses with the work "Notes on Latin American Intelligentsia" by Alfonso Reyes. In it, I develop an approach to Reyes' main contributions, as well as to questions raised by the author regarding the value and the work of the Latin American intelligentsia, relating this approach to the contemporaneity of diversity, the academy, the culture and society of Our America. The work emerges as part of the work al the Master's in Latin 
American Studies Programme, at the Institute of Latin American Studies, of the Universidad Nacional de Costa Rica (National University of Costa Rica), in addressing the Latin-Americanist thinking, along with contemporary large intellectual proposals of Nuestra America (Our-America).

Keywords: Latin American Thinking, Latin American Essay, Alfonso Reyes, Diversity.

\section{Resumo}

$\mathrm{O}$ presente ensaio consiste num analises e um diálogo com o trabalho "Notas sobre a Inteligência Americana" do autor mexicano Alfonso Reyes. O ensaio desenvolve uma abordagem sobre as principais contribuições de Reyes, e as perguntas feitas pelo pensador sobre o valor e a tarefa da intelectualidade latino-americana, relacionada á contemporaneidade da diversidade, a academia, a cultura e a sociedade da "Nossa América". O trabalho surge como parte do esforço e a tarefa da Maestria em Estudos Latino-americanos, do Instituto de Estudos Latino-americanos, em abordar o relativo ao pensamento latino-americano contemporâneo relacionado ás grandes propostas intelectuais da "Nossa América".

Palavras chave: Pensamento latino-americano, ensaio latino-americano, Alfonso Reyes, Diversidade.

\section{1}

En septiembre de 1936 frente a un público que parece estar compuesto por intelectuales latinoamericanos y europeos Alfonso Reyes desarrolla una presentación que denomina "Notas Sobre la Inteligencia America$n a$ ". Magistralmente, el autor analiza rasgos importantes de la identidad, la cultura y la intelectualidad en América Latina. Retomar este ensayo de Reyes ochenta y un años después nos solicita el tacto de reconocer un texto en su contemporaneidad, pero también nos exige el compromiso de comprender qué hemos redescubierto, descubierto, olvidado o perdido en ocho décadas convulsas y violentas.

No es mi pretensión contraponer a Reyes a una serie de interrogantes que ochenta y un años antes no eran contempladas en su quehacer intelectual, ni hacer de su ensayo un rompecabezas de figuras repintadas para constituir una nueva imagen al ser armado. Por el contrario, analizar las reflexiones de Reyes significa un rescate de su propuesta de abordaje al discurso para preguntarnos de nuevo, iexiste una inteligencia americana? Esta vez, con interrogante abordada desde la diversidad latinoamericana pueden brotar tantas respuestas como la flora y fauna del continente lo permitan.

124 Notas sobre la diversidad latinoamericana. Un ensayo Marcelo Valverde-Morales 
2

Quizá uno de los primeros aspectos que deban contemplarse sean, ique es la inteligencia?, la Real Academia de la Lengua Española define a partir de sus parámetros que la inteligencia es la "capacidad de entender o comprender", o bien, la "capacidad de resolver problemas". Lo anterior indica que la inteligencia no puede ser entendida sin ser yuxtapuesta al conocimiento, el conocimiento y los procesos para adquirirlo son entonces los parámetros de análisis de la inteligencia.

La primera disyuntiva se manifiesta en que existen diversos tipos de inteligencia y diferentes formas de conocimiento, así como existe también diversidad en los procesos de aprendizaje. La inteligencia puede ilustrarse en las capacidades entre una persona con facilidades lógico-matemáticas, otra con facilidades lingüísticas, otra con facilidades interpersonales y otra con facilidades gastronómicas, por ejemplo. En este sentido, no sería adecuado suponer que un cocinero o una cocinera latinoamericanos que nos obsequien una sabrosa causa peruana de camarón no posean inteligencia o no sean parte de la inteligencia latinoamericana.

Así como la inteligencia, el conocimiento también es diverso, en este sentido y a partir de procesos críticos y decoloniales recientes desarrollados por autores como De Sousa Santos, se plantea el rescate de los saberes ancestrales, no institucionalizados y no estructurados dentro de métodos científicos, esta propuesta ha llevado a replantear que el conocimiento disciplinar moderno puede llegar a ser tan valioso como los saberes ancestrales de poblaciones campesinas, indígenas y afrodescendientes, por ejemplo. Por lo anterior, sus saberes también componen gran parte de la inteligencia latinoamericana.

El conocimiento como entendimiento que surge desde un plano reflexivo evoluciona tomando en consideración las etapas, los aportes, los errores, las inquietudes, los absurdos y lo efímero de todo lo que en un ambiente diverso puede definir a un ser humano. El conocimiento es entonces el humano y sus circunstancias, es decir, la construcción subjetiva de métodos que se pretenden objetivos para analizar realidades también subjetivas.

La adquisición de conocimiento, por su parte, se comprende de procesos de aprendizaje que a su vez también son diversos, relativos a los tipos de inteligencia, relativos al conocimiento y a nuestras capacidades y limitaciones como seres humanos. De manera que 
para algunas personas el aprender se facilita a partir de los números, de la corporalidad o desde las letras, por ejemplo, elemento que con una adecuada creatividad nos permite plantear nuevas formas de investigar, deconstruir y construir nuestra interpretación de la realidad latinoamericana.

\section{3}

Teniendo claridad en la flexibilidad de los términos, resulta trascendental la primera advertencia de Reyes en su ensayo para sacudir un poco el polvo de la pretensión y permitirnos lavar la cara refrescantemente de cualquier juicio que pueda surgir de las interpretaciones de lo propuesto a continuación. Él nos menciona: la necesidad de abreviar, la ligereza, la confusión, la exageración, lo caricaturesco, la conversación, el agotamiento del planteo de problemas, el aporte de soluciones y el rozar temas que podrían ser universales más que meramente latinoamericanos. Es decir, Reyes propone la plática, el café universitario o de mercado siempre atento y dispuesto a reír, a entremezclar anécdotas y datos curiosos de nuestra historia, más allá del debate acalorado y serio de un salón con espectadores.

Es pues pertinente reconocer esta propuesta de construcción del conocimiento, no solamente como válida, sino además como la piedra angular de muchos buenos frutos que ha cosechado Latinoamérica. Reyes propone el disfrute del conocimiento en la hoguera de la palabra sencilla. Colorear una cantidad de temas como los que él aborda en su ensayo no podría hacerse de otro modo que no sea desde la ligereza y desde la sencillez, a un margen del método y el instrumento.

\section{4}

Nos dice Reyes que conceptos como Civilización Americana no pueden ser abordados sin contemplar la cantidad de influencias culturales que nos trastocan desde diversas "Regiones Arqueológicas", ante esto surgen interrogantes que se acercan a las dudas de nuestra identidad, idesde dónde y cómo podemos entender la palabra "Civilización"?, ¿existe o existió acaso solo una "Civilización"?, ¿es esta "Civilización" el legado de la construcción del conocimiento moderno que define nuestras instituciones y nuestros Estados?

Por otro lado, Reyes nos menciona también la "Cultura Americana" aduciendo que esto "Nos haría pensar solamente en una rama del árbol de Europa". En este sentido resulta espeluznante relacionar la Cultura 
Americana, o bien, la Cultura Latinoamericana solamente como una influencia unilateral europea. En Nuestra América converge el mundo, el legado de resistencia de la diáspora africana, la herencia ancestral de los pueblos indígenas originarios, la misma Europa (también diversa) en su inquietante curiosidad por el nuevo mundo y la influencia de poblaciones asiáticas que encontraron aquí un lugar para hacer su hogar. Es decir, más allá de una rama del árbol de Europa, Nuestra América es en sí misma un árbol, repleto de ramas, frutos, musgo e insectos, un árbol majestuoso y viejo, repleto de vida.

\section{5}

Y entonces surge un escenario, un coro y un personaje en el relato del autor, que atrapa indudablemente $\mathrm{mi}$ atención como si un teatro fantástico y listo para presentar una función inédita se presentara ante mí. Pero por un momento dudo, ies acaso un escenario, un coro y un personaje estáticos, donde cada escena se repite infinitamente? ¿Acaso no podremos ser parte del espectáculo como teatro espontáneo? ¿Es la historia presentada la historia de todos y todas?

El escenario es el tiempo, nos dice Reyes, pero parece ser un tiempo lineal, como el de una carrera olímpica donde quienes llevan la delantera son los otros, los más, los que nos indican el camino en el reflejo de su espalda, Reyes mismo lo duda, ies el tiempo europeo el único tiempo histórico posible?, se pregunta. Pero yo lo afirmo al negarlo, no, no es el tiempo histórico europeo nuestro tiempo y justamente ahí ha estado la trampa, pues nos hemos pretendido iguales en procesos y caminos cuando el legado colonial nos ha hecho crecer en el complejo, el miedo, la marginalidad, la servidumbre y la explotación. En este mundo esférico desde sus extremos, de lo hegemónico nosotros y nosotras no hemos sido parte a pesar de que en ocasiones nuestras elites repliquen los discursos de la superioridad y la competencia.

El coro descrito por Reyes es una fuente de regocijo para la humanidad y el espíritu de Nuestra América, atribuyéndole la memoria histórica de la convergencia culturalmente diversa de nuestros pueblos, en él describe la complejidad que nos caracteriza catalogándola como Sustancia Heterogénea, cierro los ojos de nuevo y lo veo, América Latina como un coro enriquecido por la diferencia que comprende los más altos valores de solidaridad y respeto, replicando al unísono que soñamos un "mundo donde quepan muchos mundos...", como lo dijera

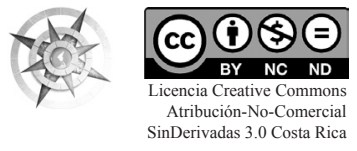


el EZLN, "Los hombres y mujeres de maíz, los verdaderos...".

La inteligencia, ya debatida como lo analizamos anteriormente, desde una perspectiva tradicional y ciertamente elitista es descrita por Reyes como atrapada en encrucijadas, o quizá más bien en "Disyuntivas" de lo que se manifestaba ante nuestros rostros como el cruce de caminos a seguir, ¿americanistas o hispanistas?, ¿Estados Unidos o Europa? Aquí caben las rupturas, como mencionamos existen variedad de inteligencias, conocimientos, procesos de aprendizaje y voluntades de aprendizaje, en este sentido invitamos a romper las variables dicotómicas que nos exigen tomar partido en debates que no nos permiten tomar la palabra.

La intelectualidad universitaria de Nuestra América tiene su lugar desde sus saberes, así como los tienen nuestros mayores indígenas y toda la amplia gama de personas que desde sus conocimientos desean aportar a nuestro propio camino.

\section{6}

Una advertencia hace Reyes a quienes lo escuchan en su relato, advertencia que bien vale la pena compartir desde el absoluto carácter con que lo hace el autor: "no nos es simpática la tendencia hacia las segregaciones étnicas" (p. 7). Y es una afirmación definitiva, una base de respeto que debe resonarnos infinitamente como un eco a lo largo de cada cordillera del continente. Sí, sabemos que en algunas de sus proclamas determinados fundadores herederos del miedo y del complejo de superioridad compartieron discursos segregacionistas y denigrantes, pero Nuestra América, que en su absoluta composición abandera y festeja el encuentro de la diversidad, debe mantenerse firme en el respeto como camino a la comunión y la paz de los pueblos.

\section{7}

Pero de súbito el relato del autor nos lleva a un complejo laberinto de puertas cerradas o en el mejor de los casos entreabiertas, reconociendo el origen en el carácter del oficio del intelectual, Reyes diferencia nuestro quehacer con el quehacer europeo, somos según el autor menos especializados, contamos usualmente con varios oficios, producimos conocimiento de forma esporádica aunque con la inspiración práctica del "aire de la calle". En esta generalización que parece un tanto atrevida hay una característica que sobresale hermosamente: "No podemos posicionarnos desde ninguna torre de marfil" (p. 8). Este elemento nos inunda

128 Notas sobre la diversidad latinoamericana. Un ensayo Marcelo Valverde-Morales

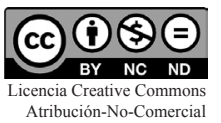


de humildad y nos invita al diálogo franco y respetuoso lejos de la ambición y la pretensión del intelectual que acorazado en su saber observa por debajo del hombro a quien en realidad camina a su lado, tan guerrillero como poeta era Roque Dalton en este quehacer diverso, tan pintora como militante era Frida Kahlo, tan ambientalista como mujer guerrera en una sociedad patriarcal era la hondureña Berta Cáceres.

\section{8}

Somos sin duda alguna nosotros y nuestras particularidades. Nuestra América ha dado frutos, nuevos sabores, nuevos colores, nuevas texturas y un nuevo alimento que refresca e hidrata el espíritu de la humanidad.

De las fatalidades que establece Reyes a partir de nuestra existencia al margen de una supuesta
"Civilización" y "Modernidad" no debe quedar más que el recuerdo. Nuestra América ya no es un satélite que gira en torno a una fuerza gravitatoria superior, debemos interiorizar nuestro propio valor, visibilizar nuestro propio aporte y pedir la palabra a la luz de nuestra inteligencia que radica en la diversidad.

Heredia, Costa Rica, noviembre de 2017

\section{Referencias bibliográficas}

Pacheco, J. (2004). Relatos del Viejo Antonio: Subcomandante Insurgente Marcos. Chiapas: Ediciones Desde Abajo.

Reyes, A. (1978). Notas sobre la inteligencia americana. México: Universidad Nacional Autónoma de México.

De Sousa Santos, B. (2009). Una epistemología del sur: la reinvención del conocimiento y la emancipación social. CLACSO. Siglo XXI Editores. 